\title{
The Study of Cultural Tourism Development Framework for Sustainable Tourism: Case Study Lampang Province
}

\author{
Rungnapa Lertpatcharapong1, Khawnnapa Sukorn² \\ ${ }^{1,2}$ Suan Dusit University \\ ${ }^{1}$ rungnapa595@gmail.com, ${ }^{2}$ khawnlanna@windowslive.com
}

\begin{abstract}
This research purpose is to study the context of cultural tourism site which facilitate to the development and tourism promotion and to present a model for development of cultural tourism management for sustainable tourism by selected Phra That Chom Ping Temple, Ko Kha District, Lampang Province as case study. The research result found that 1. Phra That Chom Ping Temple is one of the Buddhist cultural sites that still have a strong connection with the historical place and the beautiful architecture and arts objects still remain the same. 2. A Model of Cultural Tourism Management Development of Phra That Chom Ping Temple. The concept of "Bor - wonn" should be applied to houses, temples and schools to promote and support cultural tourism in communities which requires two main areas of development as follow: 1) The development of community potential and quality of tourist attractions by using community participation to improve tourism communication is the collaboration with external agencies for creating a learning process among people in the community as well as raising an awareness of preservation as a development instrument. 2) An efficiency development of networking links related to tourism development and promotion by creating the cooperation with the Education sector to promote the knowledge management system in the community and develop relationships with the government agencies and related tourism networks, including the cultural development tourism marketing together with the private agencies and administrative tourism and services sectors.
\end{abstract}

Keywords

Cultural Tourism, Sustainable Tourism, Tourism Development

Article Received: 10 August 2020, Revised: 25 October 2020, Accepted: 18 November 2020

\section{Introduction}

From the beginning, a cultural tourism has started from the awareness of the society in giving importance to Arts, cultures and traditions, and folk cultural heritage which is a result of ethnic diversity, languages and cultures in each area [1].

The tourism attraction line ways are planned to pass the several ancient civilizations and viewing the remains of world history from the remained fossils as well as to see the landmark of each places which related to their local traditions and cultures, such as archeological sites, temples, antiques, traditions, ways of life of the local people, local history and all kinds of art that represent the developed prosperity in the proper environment, and people lifestyle in each era as well. In addition, the cultural tourism also has the goal of studying knowledge from the way of people lives, customs and traditions of people in various countries. These goals will support the cultural tourism as an important basic resource and play a role in attracting tourist from various countries which support the nation income and get highest benefit return for the national economic site [2].

Thailand is provided by a well-enrichment by the several natural resources in historical and cultural tourist attractions which are an important factor to support the economic growth in tourism industrial. Thailand has not only reached the highlight of national geography resources, but has the special tradition unique in the way of life, traditions living, beliefs and rituals, and traditions arts and civilization cultures, etc. This is supplemented both Thais and foreigners tourist to visit Thailand in several tourist attractions and make the nation gain a huge of income in every year [3]. Thailand tourism industrial was succeeded that offer more opportunities to continue expand the cultural tourism industrial widely [4] [5], on the contrary, Thailand also has the unexpected negative effect problems from this rapid growth to the decadence and damage on the national environment, such as the way of life, culture and traditions way, and historical tourist attractions, etc. Recently, many researchers aware of the importance of conservation environment and interested to develop for long term sustainable [6] [7].

Regarding to the researcher, Mr. Voraphong Pookpu (2013) [8] has claimed to prevent the destruction of natural resources and local environment effect, the cultural tourism must contain with 1) Cultural tourism, 2) Environmental education process, 3) Business tourism, 4) Marketing tourism, and 6) Raising an awareness among tourists to achieve the sustainable cultural tourism. Thus, mixing and balance of preservation and cultural tourism are necessary to administrate and manage the improvement of cultural tourism in long term. Besides, technology is an important factor to support the development of culture tourism also, especially, to improve the tourism industry and all relevant parties. Thus, to prevent the losing of cultural, all relevant parties needed to responsible to the cultural tourism system and realize the opportunity risk to lose the source of knowledge as well as the local folk wisdom by conservative thinking, support and improve the cultural tourism to maintain the micro and macroeconomic for the nation as it can develop the local community income through the nation's income as well [9] [10].

In conclusion, this research is to support the culture's prevention by the management process of the cultural tourism by selected province in the northern part of Thailand where enriched the varieties of cultural resources and to 
develop the abilities to gain benefits and incomes in Lampang province where have several varieties of Thai antique and beautiful cultures as well as the outstanding artistic, traditions, and local folk wisdom within the communities. It can attract the tourist to visit from the unique calling as "Lampang, the city of never change by time to time" [11]. However, with lack of the systematic management and the communities still have no knowledge to preserve the valuable natural resources that they have and still remain an unknown city from public which caused no tourist visited to town much. The unclear vision of supporting from the government is still necessary as well as the obvious direction and guideline to develop and preserve the natural resources in surrounded area. Based on these problems, it becomes the intention to research for the guideline and planning the derection to develop the cultural tourism for long sustainable cultural tourism in Lampang province. By do the research study through the direction of cultural tourism where enrich of the pure national environment remained, as well as the other factors which supporting the local tourism in each area and develop the local business to make the local people can alive by themselves, together with the development and preservation their remained natural resource to be still useful and also balancing the benefits to all parties as well.

\section{Research Objectives}

To study the environmental context that affects tourism development and promotion and present the development model of cultural tourism management in the area Phra That Chom Ping Temple, Ko Kha District, Lampang Province, for the sustainable tourism.

\section{Research Methodology}

This research is concerned with Qualitative Research Methodology as case study in phenomenological study based in the objective as follow:

1. Research Area: The reason to select Phra That Chom Ping Temple, Ko Kha District, Lampang Province, has the approved historical evident which related to the folk regent that there have an unique outstanding in Arts and beautiful Buddhism architecture where needed to preserve. Phra That Chom Ping Temple located 23 kilometer approximately away from town, with the convenience transportations that link to another ecotourism and cultural tourism attractions where is worth studying to develop the ways to promote cultural tourism for sustainable growth.

2. Participants Key Informant group consist of:

2.1. People/ Group of people in the community which are the local people who lived in the research study area 15 peoples, such as monk, the community leader, committee, lecturer/academic researcher/ business owner and community's members. The purposive sampling will be used as research instrument and the selected criteria are national geography, social title or career, age, education and the acceptance from people in the community.

2.2. 15 Tourists by random selected as convenience sampling

3. Research Instruments

This research is to emphasis the understanding of the real situation in culture tourism which should link to the physical area of community, behavior, attitude, thinking awareness, acknowledge, to explain the concept and strategy in administration and management to improve the sustainable culture tourism. Therefore, the research instruments must consist of:

\subsection{Observation}

The observation will be used as moderate participation mean the researchers will take their role as an observer to participate and create the positive relationship among people in the community by launch the traditional and cultural activities based on the purpose to collect the primary data of tourism attractions, and to observe the local people's behavior for their relationship and participation towards culture tourism and environment within the community. The main purpose of observations is listed as follows:

- The physical character of tourist attraction that support cultural tourism

- The content of cultural and environmental that support cultural tourism

- The community participation toward cultural tourism management

3.2. Interview

An In-dept Interview will be used as Semi-Structured Interview with seven main questions as follows:

Question 1: What is the history or legends of Phra That Chom Ping Temple that has been told from the past?

Question 2: What is the community's uniqueness that has been inherited from generation to generation, such as tradition and culture activities, lifestyle, knowledge, wisdom, foods and dresses, etc.

Question 3: What is the relationship between people in the community and the temple in the field of belief, faith, inherited Buddhism events, tradition events, and preserving various culture identities, etc.

Question 4: How the community has the cooperation with the temple in the field of temple tour, tourist guide service, such as temple tour, tourist guide service as well as the preservation of Thai arts and cultures, planning and decision making for tourism management, including arrange the various of cultural activities, etc.

Question 5: Are there any other tourist attraction located nearby the community and temple?

Question 6: What is the tourism situation of Phra That Chom Ping Temple in nowadays?

Question 7: Which part of Phra That Chom Ping Temple should be developed to support and promote tourism industry for stronger and sustainable in long-term.

3.3. Sub Group Discussion is to collect data by talking with the community's members, $7-10$ peoples, on the main purpose to planning and develop the temple to be the cultural tourism resources and consider the sub topic as follows:

- problems and obstruction to develop the temple to be the cultural tourism resources.

- strength and supporting factors that facilitate and develop the cultural tourism of the temple.

- How to guide the temple to drive and develop the temple to be the cultural tourism resources.

To check the quality of research instrument should initiate by consulting with the specialist to indicate the questions issue and design the topic to collect the data, such as survey, 
observation, interview, and sub group of discussion, etc. All corrected data will be tested to find the correction of content validity by three specialists to approve the correction of language using and content coverage to find the objective of IOC (Index of item-objective congruence)

Data Analysis

After every data collection in the field Information is obtained from taking notes in this case, the information issues are considered factual and attitude.

Summarizes the raw data obtained from all recording formats. To lead to analysis and interpretation

Write a detailed description of the results of the study of the findings. Both the physical (Physical) and the (Logical) effect on the cultural tourism of the tourist attraction. And write a summary to define guidelines for cultural tourism management of Phra That Chom Ping temple.

\section{Research Result}

Research Outcomes are divided into two main parts as follows:

Part 1 - The study of the environmental context has affects the development of cultural tourism in the area of Phra That Chom Ping Temple.

Part 2 - The conclusion of tourism management model has developed the area of Phra That Chom Ping Temple and to be the sustainable tourism in long - term.

The research outcome for part 1 by analyzing and summarizing the research data in to 2 main thinking concepts which are (1) analyzing the data from the real situation based on the standard of tourism management and compare to nine key elements of Thai tourism standard index which refer to the development of Thailand tourism industry. (2) An analysis of business environment factors by using SWOT Analysis

Regarding to Part 1 of the research outcome, the research result indicated nine points that Phra That Chom Ping Temple has

Point 1

- a unique way of life, wisdom, and knowledge where can be seen in everywhere

- a beautiful of architecture and Buddhist arts object

- lack of inheritance of traditional knowledge which are original local knowledge and mostly lose from time passed time with people.

- a historical evident and history background which linked to temple and community.

- a temple which have high relationship with community and become the center to arrange the tradition activities in ever year, the nearby communities and other tourist are interested to join the events also.

- set up a small preservation group by the community but it is unofficial and lack of continuity of operations as it was gathered for temporary to arrange the specific traditional activities.

Point 2: Traditional Tourism Management Process.

- No planning for traditional tourism management process.

- No committees to take a responsibility officially for planning and manage the traditional tourism process.

- No obvious traditional tourism procession and management for developing the temple to be the tourist attraction resources.

- No plan for traditional tourism activities or events.
- Lack of human resources to take on responsibility and develop the temple to be the tourist attraction resources.

- No assessment of tourism operations and tourism satisfaction for improvement the temple.

Point 3: An administration of cultural tourism area management

- There is no allocation of responsible areas for tourist attractions with government, private and related agencies.

- Some part of tourism resources can be managed moderately in the area of tourist attraction only.

- Lack of participation from the community, association, and related clubs for continuity development.

- The temple's views are well organized, blending with existing natural resources.

- Continually developing, renovation and reconstruction at least 1-2 times per year

- No official rules or regulations required for tourists to visit various points of view in the temple

- No pictures or videos of the temple are recorded as back up information to use in the next year.

- There are many location indicated within the temple to show the valuable point of venues to visit.

- There are bounded areas for using and for tour visiting, clearly separated in specific proportions.

Point 4: Management Ability to Access Cultural Tourism Attractions.

- An access routes are all in good condition and convenient transportation through the year.

- Clear display for tourist spots provided within the temple.

The tourists can easy to access.

- Fixed open/close time is clearly inform for sightseeing visit in every day.

- Neither vehicle service available for tour visit and nor bus service with fixed time schedule available and lead the tourist to the temple.

- No information posted for guideline the way to the temple.

Point 5: Other Facilities Management

- No foods and beverages shop service for the tourist.

- Toilets are not clean, non-hygienic and number of toilet room available has not enough for the number of tourists.

- No security system or no warning to the tourist for their belongings and life safety.

- No facilities installed for elders and disabled people.

- No souvenir shop service, just only a small service point located in out of eyes site area.

- A few places for seating and installed in resting area such as benches in the garden, etc.

- A public utility system ready provided and sufficiently enough to serve the tourists.

- No first aid service point.

- Well managed and reached the standard of waste and disposal management

Point 6: Service Quality Management in Cultural Tourism Area

- Lack of human resources development to serve the tourist.

- Lack of language skills and insufficient officers to serve and guide the tourist for touring and service within the temple area.

- The local people from the communities are employed for cleaning within the temple as well as give the temple's information to the tourist. However, they are lack of temple's history knowledge, unprofessional to promote the 
temple and lack of skill to serve the tourists in all service parts.

- Obviously, no media channels to promote the internal traditional activities which organized with the community.

- Unclear of job description, no rules and regulations for staffs, and no staff uniform shirts also.

- Lack of service control according to the standard of tourism management.

- No assessment for the standard of tourism service management.

Point 7: Management of Traditional Tourism Activities.

- No meeting and planning for organizing the tourism activities which cooperated with tourism network partners. Only a small meeting with monks, committees, and people from community that has been participated the meeting.

- Lack of the standard of control to organize the tourism activities which does not cause the cultural and tradition degradation and also the way of life.

- No other supported activities, only temple tour visit and repeated activities show remain such as Thai massage, Herbal stream for health, cloth weaving, and herb knowledge promotion center, etc.

- More than 1 cultural tourism activities provided in every year but it has been promoted for 20 years already.

- Lack of supporting and sponsorship to organized the tourism activities and get income to the community.

- Lack of activities that confirm the relationship with the entrepreneurs, tourists and local people from the community.

- No clarification stating the scope and limitation of cultural tourism activities in Wat Phra That Chom Ping

Point 8: Management of community participation and partners in the cultural tourism network

- No set up group established in the community for together set up the guideline to manage the cultural tourism.

- Lack of cooperation with other external agencies, such as government, education, and private tourism sectors, etc to manage the cultural tourism systematically as well as lack of cooperation to support and development the cultural tourism of the temple. There is only the cooperation with the municipality to request supporting budget for organize the cultural activities only.

- Lack of clear support from external departments such as government and private sectors, and other related cultural tourism agencies to support and sponsor the tourism policies, supported knowledge and human resources development for tourism industry, etc.

- The community lack of income from tourism industry.

- Lack of development to improve personal knowledge and skills in tourism.

- Lack of self-awareness to realize and preserve the local traditional resources.

Point 9: Management of environmental and natural preservation

- No knowledge information giving about Phra That Chom Ping Temple to staffs and other related people in the community, including the preservation information to preserve the natural environment which is an important knowledge to support the tourism within the community.

- Lack of management supporting and environmental preservation, such as organizing campaign activities to develop and create the self-awareness to people in the community.

- Activities campaign organized for the local people to participate and maintain cleanliness in the temple area together.

- No assessment plan to assess the result of the environmental preservation

2) According to the research result, based on SWOT analysis analyze of the business environment of tourism attraction, the result indicated Phra That Chom Ping Temple as

2.1 Strengths: Phra That Chom Ping Temple located on the center of cultural tourism area which has

- historical connection link and reflect the vision to see the valuable of archaeological sites, art and antiques Various architecture etc.

- surrounded with the beauty of tourism attraction areas where unique and specific style.

- the communities surrounded the temple still maintain the local lifestyle of living which are simple, kindness, and sharing, etc. This is one of lanna charming tradition that continuing inherits time to time.

- the several communities surrounded with beautiful tourism attraction and set up the survey group to build the tradition routes already.

- charmed cultural activities and continually inherits from generation to generation.

- basic facilities that have been developed in many areas to support tourist's industry continuously. The outstanding features are

(1) winning the best toilet national award in 2016 or HAS. to won this award, it is required to pass the quality standard of cleanliness, adequate number of toilet rooms, and safely.

(2) the internal pathway within the temple must clean and clear with well manage pathway lay out sign, tidy view and well prepare for the coming tourists. For the elders and disable tourists, it is on consider and planning to improve the better service in the future.

2.2 Weaknesses: Phra That Chom Ping Temple still have problems from:

- lacking of marketing support to level up the temple in national level and international level

- lacking of community's participation to admin and manage the tourism industry

- lacking of human resources for support and together develop the tourism in community, due to most of labor age are moved to other districts and provinces, only children and elder peoples has left in community.

- lacking of communication among people in community still insufficient, no language skills practice for communicating with the tourists and no fully development of tourism industry in community.

- lacking of information point service to provide the tourism information and no guide to be a tour leader to introduce the temple and tell a story of temple's history to the tourist which make unattractive the tourist to visit.

- the community's school has no obvious role to support the tourism industry.

- lacking of technology to use for presenting the important information of tourism attractions to tourist.

2.3 Opportunities: to support the cultural tourist attractions around Phra That Chom Ping Temple: 
- decorate the beautiful route way to the temple more convenience, widely, and beautiful, etc.

- many department or educational organizations interested in processing studies and research about the area around the cultural tourism attraction resources which is beneficial to cultural tourism industry.

- the tourist attraction has its reputation in a certain interested tourist group.

- there has several tourist attractions nearby where are wellknown also such as Phra That Lampang Luang Temple, Pong Yang Temple, Lai Hin Luang Temple as well as the other tourist stopped points which are Ancient Human Garden, Folk Museum, Pong Nam Ron National Park etc.

2.4 Threats: Obstacles affecting the development of cultural tourist attractions at Phra That Chom Ping Temple:

- Insufficient of sign posting, some are broken and unclear to see.

- Lack of integration of information related to temple tourism together with the related department from external organizations.

- Seriously lack of supporting and promotion from both government departments/ organizations and other parties related to tourism.

- Lack of connection link between alliance networks of travel partners

- Lack of promoting system in academic knowledge and consultation from external agencies in order to create sustainable cultural tourism industry

The 2nd part of research summary: Format or guideline for development of cultural tourism management in the area of Phra That Chom Ping Temple, Ko Kha District, Lampang Province, for long sustainable tourism industry.

Regarding to the first part of research summary, it is significantly identify to the second part as Phra That Chom Ping Temple has several abilities for attract the tourist to visit in historical story, the unique beautiful of tourist attraction, natural environment and varieties of traditional activities through the local lifestyle of living which still remained. Refer to these factors; it is not only develop Phra That Chom Ping Temple to be the tourism resources in related to Buddhism but can be supported the growth rate of tourism industry and can use as one the instrument to develop the community for long sustainable tourism. The guideline can divide into two parts as follow:

Part 1: Strengthening the capacity of communities and tourist destinations

To make the community get more strength, the researcher found the best concept to develop Phra That Chom Ping's community by "Bo Vorn" concept as the create the cooperation within people in the community as House, Temple, and School are the center heart to make the tourism management move forward and become the cultural tourism resources by the following model picture.

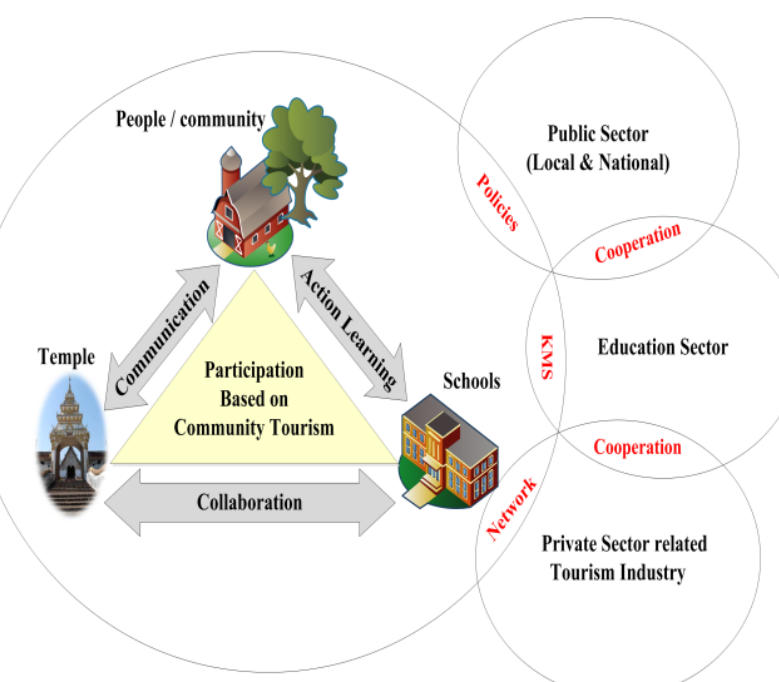

Picture 1. Model of Phra That Chom Ping Temple to be the source of cultural tourist attraction

From Picture 1, the researcher can conclude the main idea as follows:

1. Strengthen created to the community based on Community-Based Tourism Concept (CBT) by developing and encouraging people from community to participate and manage the cultural tourism at Phra That Chom Ping Temple. People are gathering to preserve their local traditional natural resources by specific the direction to develop the area to get income and benefit from the tourism industry with less damage effect to the community's cultural.

The sub-process to preserve is as follows:

1.1 Creating a community network to be the main driving system of cultural tourism management by using the principle of group process for thinking, doing and making a decision together for assessment the result.

1.2 Create an understanding of the roles and responsibilities of people in the community towards conservation of cultural heritage and tourist attractions in the community. This is to people in the community can allocate job responsibilities for joint management accurately and sustainable to cultural tourist attraction of the community.

1.3 Accelerating the development of communities to have the potential and readiness for participation in tourism management at both policy level and operating level by providing knowledge to communities and temples about traditional tourism related in all points as well as support for taking the tourism training course or filed trip to open new vision and accept new perception and awareness of value and benefit from the creation and development of tourist attractions in the community which can bring both direct and indirect benefits in the future.

2. Communication skills development for cultural tourism industry. This is the effective way to improve the communication between temple, community and external people to have the correct understanding together. It helps to support the community's uniqueness and stimulating everyone to organize many creative activities to encourage the community's tourism marketing and sustainable tradition tourism within the community as well.

3. Encouraging the collaboration between temple and school by using the tourism activities as an instrument. This is to 
create connections in the education sector to participate in promoting knowledge and organizing tourism activities by developing curriculum and learning activities in cultural tourism to stimulate the interest and enhance learning among students and the community.

4. Built up the community for learning process together with the principles of learning from real experience (Action Learning). It is to create a learning group by relying on practical actions which is creating opportunities for community group's members gain experience training from solving real problems and encourage people to develop their knowledge skills in cultural tourism management and services. Therefore, school has an important role in providing knowledge, academics, and scholarship, including to monitor the effectiveness of learning that has occurred as well.

5. Encourage all sectors in the community as well as people in the community, children and youth resulting in love, desire and feeling to preserve as the owner of the tourist attraction resources by telling the history story of the temple, suggest how to preserve and maintenance the antique architecture as well as the background story of cultural activities which lead to preserve the environment and cultural heritage of the community to remain sustainable The development of the potential and strength of the community, by using the principle, is the development of internal factors that lead the creation of tourist attractions in the community to support the growth of tourism business in the future. Nevertheless, the tourism market still needs external support. Therefore, in the second part, it is important to create a sustainable growth for Phra That Chom Ping Temple which has the following details:

Part 2: Developing the efficiency of networking links related to tourism development and promotion with the following details:

1. Education Part: Promoting the knowledge management system in the community which reply on an expert personnel and knowledge both from the community (if any) and from external organizations such as, Universities, and schools, etc. to act as counselor and to give an advice or guideline for knowledge development in cultural tourism management and cultural preservation through the process of transferring knowledge of Learning for direct successfully experiences of tourist sites or other cultural communities. From this concept process, will emphasis on historical knowledge and cultural tourism linked together to support cultural tourism management planning and formulating cultural tourism strategies suitable for the local context and the conservation of cultural tourism resources which will result in a culture of knowledge transfer from generation to generation and build the community stronger as well as create community's awareness in maintaining and sustaining the development of cultural tourist sites.

2. Government and Network Partner Involved Part: Developing and promoting the creation of tourism network promoting activities to build up the relationships between communities and external agencies or organizations in the tourism and service sector in both public and private. This is to create the cooperation in the development of tourism product and service units to be ready and able to respond to the needs of both Thai and foreign tourists. Moreover, it can create a good memorize experience and impress tourists to learn the cultural history which is a result from the community cooperation process as well.

3. Private sectors in Business Tourism Industry Part: The development of cultural tourism marketing model can be success by using marketing plan and PR promotion for private sectors, such as press releases to open the tourist attractions, organizing the special activity or broadcasting through various online medias as it is considered the most effective tool to attract and get the tourist's attention and to stimulate the growth rate of the tourism marketing as well.

\section{Discussion}

According to the research result, there have several significant interested point to develop the cultural tourism of Phra That Chom Ping Temple for long sustainable tourism industry as follows:

\section{The potential to attract cultural tourism}

\subsection{The importance factors of Tourism environment that support the tourism industry}

Regarding to the research result, it has found that Phra That Chom Ping Temple is the most oldest temple that have long history from time to time, moreover, with the beautiful spectacular of arts and architectures of Archaeological sites and ancients which have high value of history background, the community therefore can organize several cultural activities and they also can use this highlight for attract the tourist as well. Regarding to these advantages, it has related to the concept of Kanjana and Saranya Saenglimsuwan [12] stated that the historical and cultural features, location, tradition legend stories which has been told as well as various festive activities are reflected to the way of life or life condition. The well-being of people's lives are special character of cultural tourism industry. Besides, Laorit and others (2015) [13] who did the research study about the temple tour and the development concept to increase the potential of cultural ecotourism along Mekong River, Nong khai province, offer the concept idea that Temple is not only a symbol of the place for religion warship, but the Temple can be one of the tourist attraction where people and tourist can come the learn the cultural history. Thus, it is necessary to preserve the original tradition culture for the later generation to visit and see by organizing the local cultural activities and present on their eye sites to explain and give the knowledge through the important and value of the temple background as this is an advantage of competition in business tourism industry and attract the tourist from around the world to come in nowadays [14].

\subsection{Tourism Route Management for Cultural Tourism Promotion}

According to the research's result, it is significantly indicated that the tourism route way has effected to the tourist decision. From the tourist's interview, the direct route way should be convenience, short way, safe time and surrounded with beautiful view, beside, it should be easy to connect or transit to another transportation service and easy to go the other tourist attractions as well. This concept is 
similarly with the research article of Mr. Chumpol Rodjam (2012) [15] who studied about the route way to Arts and Cultural tourism attraction at Bang krui sub-district, Nonthaburi province as the tourist will consider to the convenience factors that have high value to visit by consider about the actual of distance kinlometer, gasoline price, and how long would it take time to, etc. While the research article of Thongwilai (2016) [16] also studied the element of tourism route way to tourist attraction at Pranburi subdistrict, Prachuapkirikhan province that for Thai tourist, mostly are desired to enjoy seeing the enrichment of natural environment and the beautiful view along the way to tourist attraction, as well as the privacy of the tourist are one of the element choice for making a decision to visit Pranburi subdistrict which shown the convenience of route way and other facilitates can support the tourism industry and able to applied to new dimension of tourism industry style as well, such as the linkage route way to cultural tourism, the linkage route way to ecotourism and mixed linkage route way of tourism, etc.

\section{The potential to support the cultural tourism}

Regarding to the research, it is significantly found that the local people in Phra That Chom Ping's community still lack of potential to encourage the development of cultural tourism as most of them are elder people and doing agriculture as their main career while most of adult people are moved to other town for studying and working. This is caused the community lacks of labor force and knowledge to improve and manage the tourism in community. According to this research, it is similarly concept with Sukanthasirikul and Trongpanich (2016) [12] that the quality of service has high effected to the tourist's satisfaction as well as the tourism management and organizing the interesting activities are part of encouragement to increase the growth rate of cultural tourism industry. However, the lacking problem of the potential to maintain the natural resources and the heritage of culture are considering as main negative problem to stop the development of cultural tourism, due to lack of love and spirit cherish to preserve the local tradition culture. This is similarly with the research's result of Tan and others (2018) [17] which found that the relationship with connected to the local resident help people realize to the important of cultural heritage's value. This is to encourage them to feel as the owner of the place and inspire them to be a part of preservation to develop the tourist attraction to long sustainable tourism.

Thus, this research would like to offer the idea concept to build up the community's stronger and potential to manage and improve the cultural tourism at Phra That Chom Ping Temple by using the Community Based Tourism (CBT) as an instrument to support the learning process to the community and in a cooperation with the external departments both from government and private sectors to develop the cultural tourism as well. From this concept, it is similarly with the research of Chucharn (2009) [18] about knowledge management in cultural resources by the community's leader for cultural tourism at Bann Pa Morn Community, Doi Inthanon, Chiang Mai province which found that the process to build up the strong community is to specify the direction to manage the knowledge of natural resources and applied to use it for create the ability and potential to people in community to understand and know how to make a plan, practice and able to make a conclusion of the result after complete the process, including able to teach the lesson to the later generation to make an income and benefit to community as long sustainable tourism industry. Nonetheless, regarding to the research article of Narmwong (2009) [19] who studied the concept of developed cultural tourism at Lai-hin Community (located nearby Phra That Chom Ping's community), Kho ka subdistrict, Lamprang province, presented the guideline to develop the cultural tourism, as the owner needed to take an important role to share the idea toward the management of cultural tourism's community by participating to the tradition cultural activity, and together make a planning to specific the direction to develop the local cultural tourism as well as spread out the income in community as well. Regarding to the research article of Imon, 2017 [20] which is similarly stated that the most important to develop the cultural tourism for long sustainable is to maintain the balance between the preservation of cultural heritage and support the development of cultural tourism which required to have sponsorship from the government and other external agencies and community itself. The process will start with doing the research to find the marketing needed and satisfaction from the tourist, then, planning and processing the development of all facilities such as transportation, services, accommodation to increase the ability to serve and support the tourists, besides, reorganize the organization structure for easier to manage and control the development process for further long sustainable of cultural tourism as well.

\section{The potential in management of cultural tourism attraction}

Regarding to the research, the researcher has found problems and threats of the cultural tourism development at Phra That Chom Ping Temple that lack of human resources to manage and no experience to develop the tourism, including lack of facility service, such as accommodation, no marketing and PR plan for promoting the cultural tourism also.

Therefore, for long sustainable tourism development, it is necessary to specific the direction of movement that it should be clear stated to manage by considering on the factors that needed to balance the existing cultural natural resources, tradition, and cultural activities together and get the beneficial to community. This is conform with the research concept of Hunnark (2015) [21] who studied the connection of tourist attraction in Samutsakorn province and found the element factors to link each of tourist attraction together which are incomes, benefits, and better quality of life of local people in the community, etc. Moreover, this concept also similarly with the research article of Kumwong (2012) [22] stated that to develop the cultural tourist attraction, it is needed to develop in physical elements such as promoting for safety within the tourist attractions, and public transportation, etc. while creating love spirit and cherish to preserve the original culture and environment, participating to develop the tourism industry by create the identity for dressing an uniform for vendors and staff service 
to show their tradition costume as well as in a cooperate with the government office and private sectors related, and academics papers, Pathomkarnchana and Sungraksa (2015) [23] studied about "Guideline for promoting cultural tourism with community participation" at Bang Luang Market, Bang Len sub-district, Nakhonpathom province. They found the way to support the tourism development as staff people needed to improve their skills and knowledge to cultivate and realize the preservation of natural resources, arts and culture, especially, Jit-a-sa volunteer to develop the tourism in community. For financial sector, the Sub-district or local administrative organization and other related agencies should set up the budget for support or sponsorship and process as a group team for coordinating, information service offer and support the helpdesk to the temple.

According to the cultural tourism management, there is another important guideline needed to apply for business cultural tourism industry at Phra That Chom Ping Temple which is the systematic to develop cultural tourism for creating the knowledge and how to get on closer to the tourist to impress and attract them visit tourist attraction in Thailand. This is a similarly concept of Anakesuk (2016) [24] stated that it is necessary to manage and develop the potential of natural culture resources to get the satisfaction from the tourist effectively by using the tourism marketing mix as a processing tool which are consisted of

1) Cultural Tourism Product: by emphasis on tourist products and service related to recreation activities, cultural activities and tourism services toward the tourist's needed for living together as an union community

2) Price: Price setting should be focused in accordance with price strategy for maximum benefit such as promoting local people to invest with lowest cost supply for price competition in local market as well as friendly tourism service to all coming tourists, etc.

3) Place and Distribution Channel: focusing on the distribution area to distribute the tourism products in the long term by creating the network of cultural tourism partners and using new technology such as online internet or website to promote the tourism products for selling.

4) Marketing promotion: Focusing on creating the attraction by Ad, public promotion (PR) in accordance of tourist's interest and reach directly through the target quickly as well.

\section{Recommendations}

\section{For Government department, Private Sectors, Education Department and other tourism agencies related}

1.1 Government department, entrepreneurs, and other tourism agencies related should seriously take an important role to consider and seriously support the tourism industry both policy and practical to encourage the connected cultural tourism industry by on site survey and research, develop and set up the simple visible of cultural tourism plan, as well as give the cooperation to the community, education department, and business tourism agencies for integrated tourism development program by using the tourism route way to determine the route connection which help to get the attention and attraction of tourists to visit around various cultural sites.
1.2 Government department, entrepreneurs, and other tourism agencies related should take a role as the center heart services for process and get the participation from people in the communities. They should support the development of all kind of knowledge which related to cultural tourism, including guideline local people to understand that they can get income and benefits from business cultural tourism service to develop their community and easier to cultivate their love and cherish through their original resident and the cultural heritage resources for long sustainable ever.

\section{For Local Community}

2.1 The community should set up several clubs or an independent group from the community's member to be a main group to develop all kind of dimensions the cultural tourism industry around Phra That Chom Ping Temple, for example, keep cleaning around tourist attractions, make the environment view balance with the surrounded cultural tourism area, plan and process the activities which support to the business cultural tourism industry, recruit and employ skilled people to serve the tourist and coordinate with the external tourism agencies related, etc. This is the process to encourage the awareness and alertness among people in community for unique cooperation to develop their hometown.

2.2 The community should recover their original knowledge, tradition way, activities, and antique traditional lifestyle for avoiding to lost and to become real activity which tangible and seen able, for example, build up the career development center and open the teaching course activity for trainee to serve the tourists, such as, local weaving, herb education and how to use herb for good health, and massage therapy, etc. This is help to make the tourist satisfies, more attraction, and revisiting in the future as well.

2.3 The community should get more local promotion in cultural tourism service image by present the history of each tourist attractions to create the reputation while develop language skills, manners to impress all of tourists, and other tourism service related which necessary to support the service to tourist around the world.

\section{For Tourist Attractions}

3.1 All tourism departments and agencies related should seriously take their important role to preserve the Buddhist Arts uniqueness, as well as an antique architecture, local tradition activities, cultivate love and cherish through their hometown, and preserve their local cultural resources heritage which are important supply cost for business cultural tourism industry.

3.2 All tourism departments and agencies related should in a cooperation to improve the quality of cultural tourist attractions, such as, adding for service facilities, reorganizing the area and view around tourist attraction, develop guide's ability skills for serve with good manner and able to give correct information about history and other service information, as well as help to promote the local tradition activities and invite tourists to join the events, etc.

3.3 Supporting the nearby communities to complete the business cultural tourism industry and to develop the variety 
program of product selling and cultural service as well.

\section{Recommendations for next project research}

4.1 Regarding to this research is concerned with Qualitative Research Methodology which emphasis on the using of research instruments and quality analyzing targeted on local people group in community, however, in real situation of cultural tourism, especially in the northern part of Thailand, there still have many more research point needed to study. Thus, for the further research, they should do further area of group case study by use the method of qualitative research combined with quantitative research to get more research points.

4.2 This research's result should be used in the form of cultural tourism management to be tested and applied and to find clear conclusion as well.

4.3 For further research, it should study more depth in context of problems and potential of the community which is suitable for the cultural management for more attraction and to achieve sustainability in long term.

\section{References}

[1] K. Saenglimsuwan, and S. Saenglimsuwan. "Sustainable Cultural Heritage Tourism" Executive Journal, vol. 32, no 4, pp. 139-146. October December 2012.

[2] N. Rattanasuwongchai. (2011). "Cultural tourism development strategies". Manutsayasat Wichakan journal, vol 18, no, 1, pp. 31-50. January - June 2011.

[3] Department of Tourism. "Quality Standard Assessment Manual Cultural attractions". Bangkok: Department of Tourism. (2016).

[4] World Tourism Organization. "Tourism and culture". Retrieved October 5, 2018, from https://www.unwto.org/tourism-andculture.

[5] G. Richard. "Cultural tourism: A review of recent research and trends". Retrieved May 14, 2018, from https://www.sciencedirect.com/science/arti cle/abs/pii/S1447677018300755.

[6] T. Butts, and S. Singh. "Sustainable tourism as a tool for conservation and protection of the Amazon rainforest in Guyana?." Worldwide Hospitality and Tourism Themes, vol 2, no 2, pp. 173-185. April 2010.
[7] N. B. Kidder, and D. L. Spears. "Tourism: A tool for biodiversity conservation in the Cape Horn region". Paper presented at the 16th Graduate Students Research Conference, Huston Texas, Conrad N. Hilton College of Hotel and Restaurant Management, University of Houston School of Hotel and Tourism Management, The Hong Kong Polytechnic University, 2011.

[8] V. Pookpu. "Develop guidelines for collaboration and networking. Community based tourism mentoring organization". The Thailand Community Based Tourism Institute, 2013.

[9] Department of Tourism. National Tourism Development Plan 2012-2016. Bangkok: Department of Tourism, 2011.

[10] R. Nunkoo, and H. Ramkissoon. "Developing a community support model for tourism". Annals of Tourism Research, vol 38, no 3, pp, 964-988. July, 2011.

[11] Tourism Authority of Thailand. (2015). Lampang province information. Bangkok: Tourism Authority of Thailand, 2015.

[12] K. Sukanthasirikul and W. Trongpanich. "Cultural Tourism Experience on Customer Satisfaction: Evidence From Thailand". Journal of Economic and Social Development, vol 3, no 1. pp. 17-25. Jul 2016.

[13] Y. Laorit, S. Champadaeng, and K. Paensoi. "Temple Tour: Guidelines for Development potential of cultural EcoTourism along Mekong riverside, Nongkhai province". Graduate Studies Journal, vol 12, no 57, pp. 15-176. April July 2015.

[14] Y. Liu, and C. Lin. "The Development of Cultural Tourism: A Review of UK Experience". Tourismos: An International Multidisciplinary Journal of Tourism, vol 6, no 2, pp. 363-376. January, 2011.

[15] C. Rodjam. "The Cultural Tourism Program in Bang Kruai District, Nonthaburi. (Research report). Nonthaburi: Rajapruk University, 2012. 
[16] B. Thongwilai, "Exploratory Factor Analysis of Travel Routes for Thai Tourists in Pranburi, Prachuap Khiri Khan Province". (Master degree) Bangkok: Bangkok University, 2016.

[17] S. K. Tan, S. H. Tan, Y. S, Kok and S. W. Choon. "Sense of place and sustainability of intangible cultural heritage- The case of George Town and Melaka". Tourism Management, vol 67, pp. 376-387. August 2018.

[18] K. Choochan. "Knowledge management of culture resource by community leadership for tourism: Ban Phamon Community, Doi Inthanon, Chiangmai Province". (Master degree, Thammasart university: Bangkok.) 2009.

[19] P. Narmwong. (2009). Study of guidelines for tourism development, community culture, Lai Hin Amphao Koh Kha, Lampang Province. (Master Degree, Mae Jo University: Chaing Mai). 2009.

[20] S. S. Imon. "Cultural heritage management under tourism pressure. Worldwide Hospitality and Tourism Themes, vol 9, no 3, pp. 335-348. June 2017.

[21] C. Hunnark. "A Study of the connection of Tourist sites in Samut Songkhram Provice”. Valaya Alongkorn Review, 5(2), 113-124. July - December 2015.

[22] K. Kittimasak. "Strategies to Develop Cultural Tourism: A Case study of Wat Banghuasue Community, Prapradang District, Samutprakan Province". (Master degree, Dhonburi Rajabhat University: Bangok). 2012.

[23] C. Pathomkarnchana, and N. Sungraksa. "Guidelines for the promotion of cultural tourism participation of community Bangluang Banglen district Nakhon Pathom province". Academic Services Journal, Prince of Songkla University, vol 26, no 1, pp. 118-129. January - April, 2015.

[24] B. Anakesuk. "Yol Yeam Yearn Yow: Concepts and theories on cultural tourism. Pisanulok, Thailand: Narasaun University Publishing. 2016. 